EESTI NSV TEADUSTE AKADEEMIA TOIMETISED. VI KOIDE BIOLOOGILINE SEERIA. 1957, NR, 2

ИЗВЕСТИЯ АКАДЕМИИ НАУК ЭСТОНСКОИ ССР. ТОМ VI СЕРИЯ БИОЛОГИЧЕСКАЯ. 1957, №2 2

\title{
KURVITSALISTE LÄBIRÄNDEST VOOREMAA JÄRVESTIKUS
}

\section{R. LING}

Ida-Eesti vooremaastiku arvukad järved moodustavad läbirändel viibivatele kurvitsalistele olulise vahepeatusala kevad-, eriti aga sügisrändeperioodil. On tōenäoline, et suur osa kurvitsalisi, jōudnud rändeteekonnal Peipsi järveni, jätkab oma sügisrännet üle Vooremaa järvede Võrtsjärve suunas ja selle tagamaade kaudu Balti mere rannikule.

Käesolevas artiklis käsitletakse vaid osa Vooremaa järvedest. Kõik järved nimelt ei ole oma tingimustelt kurvitsalistele rändepeatuspaikadena vōrdsel määral sobivad. Sellisteks kurvitsaliste poolt vähekülastatavateks järvedeks on näit. Elistvere, Prossa ja Pikkjärv, nähtavasti ka Saadjärv, Raigastvere ja Kaiavere järv. Pearōhk kurvitsaliste rände uurimisel on asetatud Pupastvere järvele ja Soitsjärvele kui kurvitsaliste tähtsamatele koondumiskohtadele.

Kuigi Vooremaa järvede linnustiku uurimine algas juba 1936. a., on lindude rände kohta selles järvestikus varemkogutud andmed vôrdlemisi katkendlikud. Varasemate uurijate peamiseks huviobjektiks oli Soitsjärve linnustik. Sõjajärgsel perioodil on uurimised tihenenud ja kordunud mitu aastat järjest samadel aastaaegadel, kusjuures on pühendatud tähelepanu ka lindude rändele.

Varasematest materjalidest on käesolevas ülevaates kasutatud A. ja E. Kumari andmeid Vooremaa järvede linnustiku kohta aastatest 1937, 1939, 1947, 1948, 1949 ja 1953 ning E. Talve andmeid 1940. ja 1942, aastast. Isiklikult kogutud vaatlusandmed pärinevad 1955. ja 1956. aastast; mõlemal aastal uuriti Vooremaal nii kevad- kui ka sügisrände.

Järvede lühike iseloomustus. Kōnesolev järvede rühm (Pupastvere färv, Saadjärv, Soitsjärv, Raigastvere ja Kaiavere järv) asetseb intensiivselt ekspluateeritava kultuurmaastiku keskel. Põllud, heina- ja karjamaad ulatuvad kohati vahetult kaldajooneni.

Pupastvere järv (foto 1) on viiest vaatlusalusest järvest väikseim. H. Riikoja $\left[{ }^{3}\right]$ andmeil oli ta pikkus vaid $1100 \mathrm{~m}$, suurim laius $300 \mathrm{~m}$, pindala 20,5 ha ja suurim sügavus $2,25 \mathrm{~m}$. Tänapäeval ei ole need arvud enam kehtivad: 1955 . a. kevadtalvel kaevati järvest ca $70 \mathrm{~m}$ kaugusel, paralleelselt lõuna- ja läänekaldaga, suur magistraalkraav järve ümbritsevate soiste maa-alade kuivendamiseks. Selle tagajärjel hakkas vesi järves kiiresti alanema. Praegu on järv maksimaalse veeseisu ajal vaid umbes $30 \mathrm{~cm}$ sügav ja ta veeseisu mōjustavad oluliselt sademed. Järve kinnikasvamisprotsess on eriti hoogustunud pärast magistraali süvendamist 1956. a. suvel. «Pōhiatu» mudakiht (mis on levinud kogu järve ulatuses) ei vōimalda kalda poolt veepiirile läheneda. Köige veerohkem on Pupastvere järv kevadel sulavete kogunemise perioodil. 1955. a. valitsenud põuasel suvel kuiunes järv juba juunikuu jooksul suureks mudaväljaks, kus vabavett esines piiratud määral vaid idaosas. 1956. a. sademeterikkal suvel esines aga vabaveealasid enam-vähem võrdses vahekorras mudapaljanditega.

S oits järv (foto 2) on H. Riikoja andmeil $4400 \mathrm{~m}$ pikk, ta suurim laius on $1000 \mathrm{~m}$, pindala 223,0 ha, suurim sügavus $8,0 \mathrm{~m}$. Soitsjärvel, samuti nagu Pupastvere järvel, kulgeb kinnikasvamine kiires tempos. Kaldaveetaimestik on enam-vähem pidev ja lopsakas kogu järve kaldajoone ulatuses, avatud kallast esineb piiratult. Ulatuslike sademetega seosesolevaid veetaseme kōikumisi esineb, kuid vōrreldes Pupastvere järvega on nad vähem märgatavad. Sademetevaestel suvekuudel laieneb mudakallas (paiguti ka liiva-peenkruusakallas) taganeva vee arvel $6-8 \mathrm{~m}$ võrra, moodustades nn. «kurvitsarandu» (näit. Kursi rand kirde- ja Kangru rand kagukaldal). Madalamates järveosades (eriti otstes) tekib samal ajal hundinuia-tarna saarte vahele arvukalt mudapaljandeid ja järve keskosades jäävad veepinnale ulatuslikud Chara-niidud. Sel moel kujuneb rändavatele kurvitsalistele soodsaid peatuskohti kogu järve ulatuses.

Järvest väljavoolava Kursi oja süvendamine, mis lōpetati 26. septembril 1956, kutsus Soitsjärves esile tunduvaid muudatusi. Ohe nädala jooksul oii veepind al anenud juba ca $50 \mathrm{~cm}$ vōrra ja alanemine jätkus, kuigi aeglasemas tempos. Esimesele Soitsjärve alla- 




Autori foto

Foto 1. Vaade Pupastvere järvele idakaldalt lõunasuunas Charadrius dubius'e biotoop. 15. mai 1956.

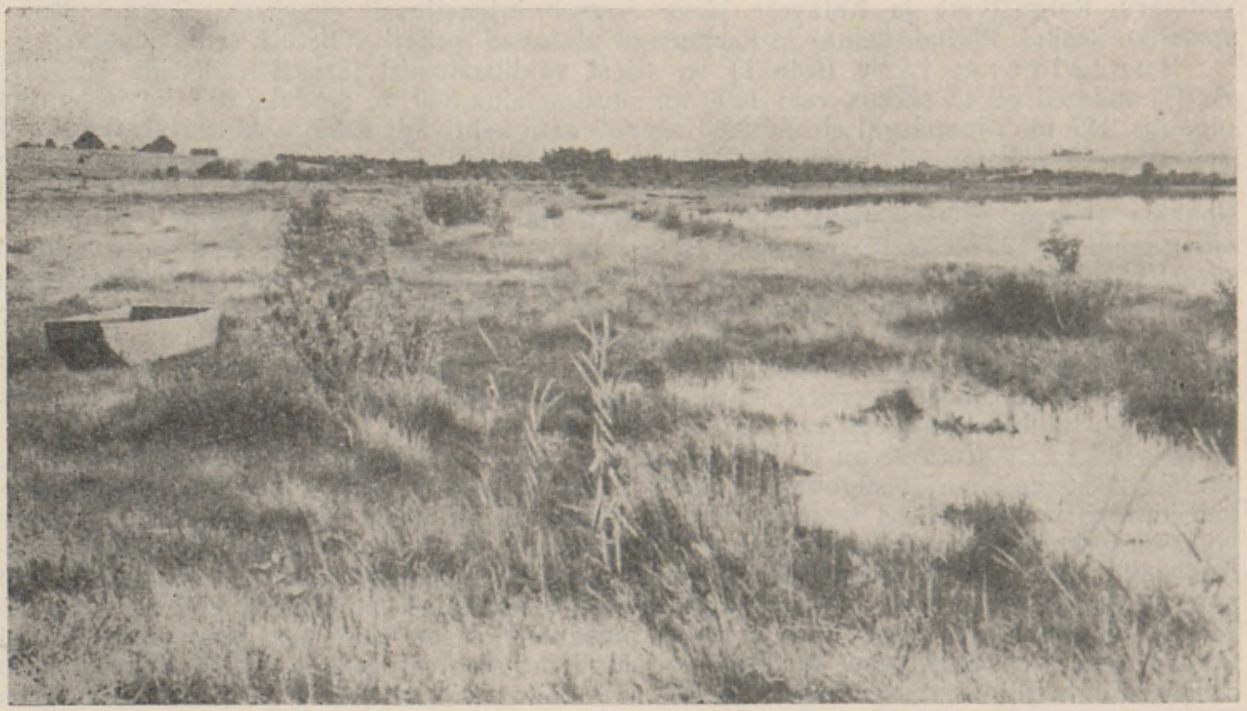

Autori foto

Foto 2. Soitsjärve kirdekallas, vaade SO. Rändekurvitsaliste Charadrius dubius'e, Philomachus pugnax'i, Tringa glareola biotoop. 8. sept. 1956. 
laskmisele 1929. a. (sama oja kaudu) järgnesid kiiresti silmatorkavad muutused järve kinnikasvamisprotsessis ja linnuelus. Sedasama on siin oodata jälle.

Siinkohal ei anta Saadjärve, Kaiavere ja Raigastvere järve iseloomustust, sest käesolevas artiklis mainitakse neid järvi vähestel juhtudel.

\section{Vooremaa järvestikust läbirändavate kurvitsaliste süstemaatiline ülevaade}

1. Ki ivitaja, Vanellus vanellus (L.). Haudelind ja läbirändaja mōlemal rändeperioodil. Pesitsevate paaride arv tihe järve ääres ulatub $3-5$ (Pupastvere järv) kuni ca 10 paarini (Soitsjärv).

Saabub kevadel kurvitsalistest esimesena (1955, a. 7. aprillil, 1956. a. 7. mail), aga läbiränne on nōrk; pesitsejaid saabub pärast esimesi märkamatult juurde. Juunikuu esimesel poolel, kui lōpeb kohalike lindude pesitsemine, algab varasuvine ränne. Rändesalkade suurus kôigub siis $15-60$ isendi vahel.

Sügisrändel on kiivitaja Vooremaa järvedealal kōigișt kurvitsalistest kõige arvukam, ühtlasi kõige pikema rändeperioodiga liik. Pupastvere järvel oli läbirändajate maksimaalarvudeks: 1955. aasta 14. juunil 152 is.*, 3. augustil 188 is., 1. septembril 150 is. Mõnikord esineb täielikke pause rändeliikumises (augusti lōpp - septembri algus 1955). Pärast vaheaega ilmuvad kiivitajad eelistatud peatuspaikadesse uuesti suurtes salkades. Ränne hakkab septembri keskel vaibuma ja lakkas 1955. a. septembri lōpul. 1956. a. rändasid hilised kiivitajad (2 is.) Soitsjärve kohal veel 2. oktoobril.

2. Plü ü, Squatarola squatarola (L.). Täheldatud 7. ja 9. juunil 19391 is. Soitsjärvel Kursi rannikul koos veetallajatega (E. Kumari, suuliselt). Viimaste järvelt kadudes püsis plüü veel vähemalt 2 päeva samal kohal. Sügisrändel liiki seni täheldatud ei ole.

3. $\mathrm{P}$ öh j.a rü üt, Pluvialis apricarius altifrons (Brehm). Esineb vähearvulise läbirändajana sügisel. Seni on märgitud väikesi salku 1955. aastal Pikkjärve ja Soitsjärve ääres septembris, Pupastvere järvel oktoobri alguses. 1956. aastal rändasid pōhjarüüdad üle Saadjärve 17. ja 18. septembril ühekaupa.

4. Li iva- ja t undrat ü11, Charadrius hiaticula L. et tundrae (Lowe). Esinevad senistel andmetel läbirändajatena ainult Pupastvere järvel. Pole selge, kui suur osa Vooremaal läbirändavaist isendeist kuulub liivatüllide ja kui suur osa tundratüllide hulka. Kevadel pole neid seni kohatud. Peipsi järve loodeosas on liiki aga ka kevadrändel märgitud $\left[{ }^{4}\right]$.

Sügisrändel saabub tundratüll Pupastvere järvele augusti teisel dekaadil (1955. aastal 13. augustil) vōi augusti alguses (liivatüll?) (1956. aastal 3. augustil). Peatub siin algul väikeste salkadena ja esineb sageli koos alpi risladega, kellega moodustab nōrgemini vôi tugevamini liitunted rändeseltsinguid. Uhel juhul on täheldatud segasalka 1 tundratüll, 1 alpi risla (ad.) ja 1 leetelind (9. oktoobril 1955), kes püsis kohal vähemalt 5 päeva. Uksiksalkades tundra- või liivatülliga on täheldatud ka kōvernokk-rislat (7. ja 10. augustil 1956).

Rănne on eriti intensiivne augusti keskpaigast alates ja toimus 1955. aastal pika ajavahemiku jooksul laineliselt: 15. ja 21. augustil kuni 36-ni ulatunud isendite arv langes 4. septembriks 10-ni, 13. septembril oli Pupastvere järvel 20 is. (juv.), kusjuures alates 21. septembrist vähenes läbirändajate arv pidevalt. Oktoobri alguses vōis rännet lugeda lõppenuks (viimane märgitud 5. oktoobril). 1956. aastal algas ränne varem (3. augustil) ja saavutas kulminatsiooni 9.-24. augustiks (salkades $22-55$ is.). Vanalindude ränne vaibus augusti lōpus, noori rändas septembri keskpaigani.

5. Vä i k et ü 11. Charadrius dubius curonicus Gm. Kuulub Vooremaa järvestikus nii pesitsejate kui ka läbirändajate hulka (Soitsjärv, Pupastvere järv, Saadjärv). Saabub mai algul (näit. märkis E. Kumari liiki Soitsjärvel 1949. aastal 3. mail, kui esines veel öökülm). Kevadränne näib kestvat mitu nädalat. Vörreldes linnu praegusaegset esinemist Soitsjärvel E. Kumari andmetega 1937. ja 1939. aastast, ilmneb selgesti, et ta arvukus on Vooremaa järvedel tublisti langenud. Mudapaljandid Soitsjärve kirde- ja kagukaldal, kus väiketüll varematel aastatel hulgaliselt pesitses ja rohkearvuliselt rändel peatus (foto 2), on nüüd tugevasti murustunud ega paku sellele paljasrannikute karakterliigile enam esinemisvôimalusi. Praegusaegset pesitsuskoostist Soitsjärvel võib hinnata 2-le ja Pupastvere järvel 3-5-le paarile. V-ôrdluseks olgu öeldud, et maksimaalne paaride arv oli Soitsjärvel 1939. aastal, millal E. Kumari loendas 7. ja 9. juunil vähemalt 30 paari (kõik arvatavasti siiski ei pesitsenud). Saadjärvel pesitses see liik 1948. aastal (A. Kumari, suuliselt).

Niethammer $\left[{ }^{2}\right]$ peab väiketülli eranditult piki jōgesid ja järvi rändavaks ning mererannikut vältivaks liigiks. Vooremaa järvede kaudu on kevadränne nōrk. Pesitsejad saabuvad maikuu esimese poole jooksul, jäädes kohe paigale. 1956. aastal stabiliseerus lōplik pesitsuskoostis Pupastvere järvel 15. maiks, Soitsjärvel 20. maiks.

Salkade suurus sügisrände ajal on $3-7$ is. Kuigi on täheldatud väiketülli ühissalku 
(toitumise ajal) peamiselt värbrislaga, ka liivatülli ja alpi rislaga, näib seos teiste kurvitsalistega olevat lōtv. Eriti välditakse suuremaid liike. Lennusalgad on enamasti liigipuhtad, välja arvatud juhud, kus äkilisi üleslende tingib röövlindude (raudkull, lõopistrik) ilmumine järve piiridesse.

Rändeisendite lisandumist paiksetele on Pupastveres täheldatud juuli keskel (1955, 1956), kusjuures ilma puhanguliste liikumisteta ränne vältab augustikuu läbi. Kohalpesitsejad kaovad järvelt valdavalt augusti teisel poolel (1956. aastal ei esinenud neid enam 20. augustil). Viimast korda täheldati läbirändajaid Soitsjärvel 12. augustil 1955. ja Pupastvere järvel 1. septembril 1956. aastal.

6. Kivirullija, Arenaria $i$. interpres (L.). Ainult üks kord $=9$. juunil $1939-$ nägi E. Kumari üht isendit Soitsjärvel, mis tōestab, et kivirullija võib ka meil olla läbirändaja siseveekogudel.

7. Kōvernokk-risla, Calidris ferruginea (Pont.). Satub Vooremaale harva sügisrändel. 30. ja 31. augustil 1947 täheldati liiki A. Kumari (suuliselt) poolt Soitsiärvel.

Pupastvere järvel esines kõvernokk-rislasid paari isendi näol teiste kurvitsalistega (peamiselt alpi ja värbrisla) ühissalkades 28, juulist - 10. augustini 1956 kuuel korral. Pärast 10. augustit 1956 liik puudus.

8. Alp i risla, Calidris a. alpina (L.). Iga-aastane arvukas läbirändaja Vooremaa järvestikus. Oksikuid adultseid isendeid on eri aastatel esinenud Soitsjärvel ka pesitsusperioodil. Neid võib pidada hulguisendeiks, kellele järve tüüpiline «kurvitsarand» on pakkunud sobivaid vōimalusi peatumiseks isegi pikema aja jooksul. Kuid 7. juunil 1939 pidas E. Kumari siin üht paari ka pesitsejaks, sest linnud käitusid nii ärevalt, nagu oleksid neil pojad läheduses.

Alpi risla jōuab Vooremaale mai esimesel dekaadil, esinedes kevadrändel tavaliselt üksikute isenditena (mitmel aastal, nii näit. 1956. a., teda ei nähtud). Ohineb teiste arvukamalt esinevate kurvitsalistega (näit. tumetilder) ajutisteks seltsinguteks, kusjuures edasilendamine toimub siiski eraldi.

Sügisrändel on liik arvukas. 17. juulil 1955 (Soitsjärv) esines 14 is. ja enamgi, esialgu liigipuhastes salkades. Rännet alustavad vanalinnud. Pupastvere järvel esines 1956. a. juulikuu teisel poolel pidevalt suuri (kuni 30 is.) salku, 28. juulil isegi 60 is. salgas. Noored isendid ilmuvad juulikuu viimastel päevadel (1956); samal ajal algab vanalindude märgatav vähenemine rändesalkades. Augusti algul liituvad nendega liiva- vōi tundratüllid, alpi rislade arv langeb siis järsult ja rände kōrgpunkt on möödunud. Alpi rislade ja liiva- või tundratüllide vahekord ühissalkades on sagedasti 1:1 (näit. Pupastveres 21. augustil 195525 . ad. + juv. alpi rislat ja 25 tülli, 13. augustil 20 alpi rislat ja 19 tülli, 10. augustil 19564 alpi rislat ja 4 tülli jne.). Eriti tugevasti on liitunud väikesearvulised segasalgad.

Augusti esimesel dekaadil vaibub alpi rislade ränne järjest. Oht hilist alpi rislat võis näha 5.-9. oktoobrini 1955 Pupastvere järvel väikeses kurvitsaliste segasalgas. 1956. aastal kohati viimaseid alpi rislasid Vooremaal 14. septembril.

9. Vä r bris la, Calidris temminckii (Leisl.). Varasemate andmete (A. Kumari) järgi kohati 31. juulil 1948 9-isendilist rändesalka Saadjärvel nn. «kiivitajarannas». Uks isend on kollekteeritud kevadrände ajal 27. mail 1949 Soitsjärve äärest Kursi lagerannalt.

Kõige täielikumad andmed värbrisla rändest saadi 1956. a. sügisel. Liik esines siis püsivalt Pupastvere järvel. Esimesed neist saabusid 11. juulil. Esineb üksinda ja väikeste salkadena $(2-10$ is.), enamasti eraldunult teistest kurvitsalistest. Seltsinguis teiste liikidega on prevaleerivaks väiketüll (toitumissalkades), teisel kohal alpi risla (ka lennusalkades). Ränne lakkab septembri alguses.

10. S u u r ris l a, Calidris c. canutus (L.). Esineb kevadrändel meil üldiselt vähearvuliselt, ta sattumine Vooremaale on üsna juhuslik. E. Kumari kohtas 13. juunil 1947 üht isendit Soitsjärve Kursi rannikul ja käesoleva artikli autor kohtas 4. ja 6. juulil 1955 üht isendit Pupastvere järvel. Sügisrändel on suurrislat märgitud Pupastvere järvel 1956. aasta 5. ja 10, augustil ning 14. septembril à 1 is., kes hoidusid eraldi teistest kurvitsalistest.

11. L e et eli nd, Crocethia alba (Pall.). Jälgitud vaid sügisrändel. Viibis üksiku isendina 5. ja 9. septembril 1955 (ilmselt ka vahepealsetel päevadel) Pupastvere järvel koos ühe alpi rislaga ja ühe tundratülliga lahutamatus rändesalgas.

12. Tu tka s, Philomachus pugnax (L.). Kuigi liik nii kevad- kui ka sügisläbirändel Vooremaa järvestikus esineb, kohtab teda massilisena siin harva. Näit. 8. mail 1948 esines Soitsjärvel ühe päeva jooksul üle 100 isendi (A. Kumari). Tavaliselt moodustuvad rändesalgad $10-20$ ja ka văhemast arvust isendeist. Pesitsemise kohta puuduvad andmed, kuid suvel on hulkuvaid isendeid kohatud Vooremaal mitmesugustel aegadel. Tõusva intensiivsusega rännet võib märgata augusti teisest dekaadist alates. Kui tutkad leiavad sobiva toitemaa, peatuvad nad järvedel isegi mitu nädalat (1955). Septembri teisel poolel raugeb ränne, oktoobris võib veel kohata üksikuid hiliseid peatujaid. 1955. aastal lendasid viimased neist Pupastvere järvelt ära 21. oktoobril (2 is.). Eriti vähearvuliselt esines tutkaid 1956. a. sügisel: Soitsjärvel on kuni augusti lõpuni märgitud vaid 30 ja Pupastverel ca 20 is. 
13. T u m eti ld e r, Tringa erythropus (Pall.). Läbirändajate arvus esineb eri aastatel silmatorkavaid kõikumisi. Nii on A. Kumari 1948. a, mais Soitsjärvel kahe päeva jooksul (8. ja 9. mail) loendanud 35 is., kes peatusid väikeste salkadena peamiselt põhja- ning idakaldal. Sel ajal näib olevat rände kõrgpunkt, mis olenevalt kevade tingimustest vōib ka hilineda. Teistel aastațel, kuni 1955. aastani, ei ole maikuus ekskursioone Vooremaa järvedele peaaegu toimunud. Aastail 1955 ja 1956 tumetildri kevadine läbiränne peaaegu puudus.

Tavaliseks nähtuseks on tumetildri (nagu enamiku teistegi tildrite) viibimine Vooremaa järvestikul kogu suve. Eriti rohkearvuliselt esines tumetildrit 1955. a. suvel Pupastvere järvel. Teistel järvedel (Soitsjärv, Saadjärv) võib märkida vaid üksikuid.

1956. a. varasuvist ja sügisrännet täheldati ainult Pupastvere järvel. Alates 15. ja lôpetades 24, juunil esines hundsulestikus isendeid järvel pidevalt (kuni 17-isendiliste salkadena, salgas enamasti vähem kui 10 is.). Pärast pikemat vaheaega ilmusid tumetildrid uuesti 14. juulil ja püsisid järvel pidevalt kogu augustikuu. Siis olid salgad aga juba väikesed ( $2-5$ is.) ja teistest kurvitsalistest esines salkades enamasti punajalg-tilder, harva mudatilder. Aastal 1956 kadusid tumetildrid Vooremaa järvestikust septembri alguseks. Köige hilisem tähelepanek pärineb kahe rändel olnud isendi kohta 10. septembrist 1955 .

14. P un a ja $1 \mathrm{~g}-\mathrm{ti} 1 \mathrm{~d}$ e r, Tringa $t$. totanus L. Saabub Vooremaa järvestikule aprilli lōpul (1948. a. 24. aprillil) väheste isenditena, sageli paariti läbirändel. Alates 1949. aastast (võimalik, et juba varemast ajast) pesitses Soitsjärve pōhjakaldal üks paar järjekindlalt. 1956. aastal aga polnud neid.

Teistelgi järvedel (Pupastvere ja Raigastvere järv) vōib suvel kohata üksikuid hulkuvaid isendeid. Kohalikud isendid on põhjapoolsete läbirändajate saabudes juba kadunud.

Sügisränne kulgeb kõikide-Vooremaa järvede kaudu, kuid vähese intensiivsusega. Esimesi sügisesi läbirändajaid vōib Vooremaa järvedel kohata juuli lõpus (1955) või keskel (18. juulil , 1956). Nad esinevad üksikult vồi mōnekaupa, seltsides enamasti tumetildriga, kuid kaovad juba augusti esimesel poolel (1956. aastal ei esinenud neid pärast 7. augustit). Aastal 1955 aga esines liik Vooremaal veel septembri esimestel päevadel.

15. S o otilder, Tringa stagnatilis (Bechst.), sattus eksikülalisena meile 1949. a. kevadel, mil lasti Soitsjärvel 2 is. - üks 14. mail ja teine 12. juunil.

16. Heletilder, Tringa nebularia (Gunn.). Arvukamaid läbirändajaid Vooremaa järvestikus nii kevadel kui ka sügisel. Peale rändavate isendite koguneb mōnedele veekogudele mittepesitsevaid, hulguelul viibivaid linde. Nende arv ulatus näit. Pupastvere järvel 1955. a. juuli keskpaigaks mōnekümne isendini, mis nii väikesel veekogul on silmatorkav arv ja on seletatav heade toitumisoludega. Hulkujaid esineb ka Soitsjärvel (1953. a., E. Kumari).

Kevadrände kulminatsioon langeb Vooremaal mai esimesse dekaadi (1937., 1948. ja 1949. a.). Sel ajal on ühe- vôl kahekaupa hoiduvaid, teistest kurvitsalistest eralduvaid heletildreid näha kōige rohkem Soitsjärve põhja- ning idakaldal, kus nad aga ei näi kestvamalt peatuvat. 1956. aastal oli selle liigi kevadränne kōrgpunktis maikuu viimasel dekaadil.

Juulikuu esimene pool toob Vooremaale esimesi sügisrändel viibivaid heletildreid. Sügisrändel augusti esimesel poolel on heletilder kõige arvukamaks liigiks teiste suure. mate tildrite hulgas. Seejuures ei ületa salkade suurus enamasti 3 is. ja salgad on valdavalt liigipuhtad. Ohel juhul on täheldatud püsivamat segasalka: 1 heletilder, 1 veetallaja ja 2 noort alpi rislat (Pupastvere järvel 1. septembril 1956), kusjuures heletilder asus teiste etteotsa nii üleslennul kui ka liikumistel veekogu piirides. Ka kooslustes mudatildriga on täheldatud samuti heletildri juhtivat osa.

20. augustist alates muutub heletilder haruldasemaks. Viimast heletildrit võis Pupastvere järvel märkida 1955. a. 13. septembril ja 1956, a. 1. septembril. Siitpeale ei kohatud liiki ka mujal.

17. Metstilder, Tringa ochropus L., on mōlemal rändeperioodil vähene, aastail 1955 ja 1956 esines teda aga südasuvel sagedasti, peamiselt Pupastvere järvel.

Saabumine algab aprillis (25, aprillil 1948 juba kohal - A. Kumari, suuliselt) ja kestab maikuu loppuni (1956. a. täheldatud veel 5. juunil). Aralend algab juuli esimesel poolel (Pupastvere järvel 10. juulist 1956) ja on intensiivne kuu loppuni. Seltsib eriti mudatildriga. Augustikuu algul hakkab ränne vaibuma, 1955. aastal ei nähtud seda liiki enam pärast 21. augustit, 1956. aastal pärast 18. augustit.

18. M u datild er, Tringa glareola L., esineb Vooremaa järvestikus nii läbirändajana kui ka suvekülalisena mărgataval arvul. Kuigi juba 1939. aastast püsib kahtlus ühe paari pesitsemise kohta Soitsjärve läänekaldal, puuduvad seda tōendavad materjalid.

On varajane saabuja ega hooli isegi lume esinemisest või keltsast (nagu näit. 6. mail 1955). Eelistab tegutseda segasalkades teisté tildritega ja tutkaga. Aastal 1955 esines kogu juulikuu jooksul massiliselt (kuni 100 is.) Pupastvere järvel, kusjuures ilmselt oli tegemist samade isendite pikemaajalise kohalviibimisega. Nendega hakkasid juulikuu keskel liituma rändel viibivad mudatildrid. Juulikuu lõpul (nii 1955. kui ka 1956. aastal) algas mudatildrite elav liikumine. -Nüüd ilmus see liik märgataval arvul ka Soitsjärvele 
(eriti 1955. a.). Tegutseb kuni 10 -isendiliste salkadena mitte ainult järve kaldail, vaid ka selle taimestikus - tarnasaartel, ujutaimede lehtedel, Chara-niitudel ja taimestikuvahelistel mudapaljanditel. Augustis on läbiränne elav (7. augustil 1956 - Pupastverel 66 is.), aga juba septembri alguses muutub mudatilder haruldaseks (1956. a. koguni puudus). Pupastvere järvelt lahkus viimane isend 1955. a. 10. septembril, 1956. a. märgiti teda viimati 24 . augustil.

19. Vihit aj a, Actitis hypoleucos (L.), viibib läbirändel enamasti üksikult, harva seltsides teiste kurvitsalistega (alpi risla, mudatilder), ja ilmutab suurt püsimatust, mistõttu peatub sama veekogu piirides lühikest aega.

Kevadel jõuab vihitaia Vooremaale mai alguses. Pesitsemisest siin ei ole kindlaid andmeid. Juulikuus (1955) on märgitud rohkelt esinevate kurvitsaliste hulgas seda liiki

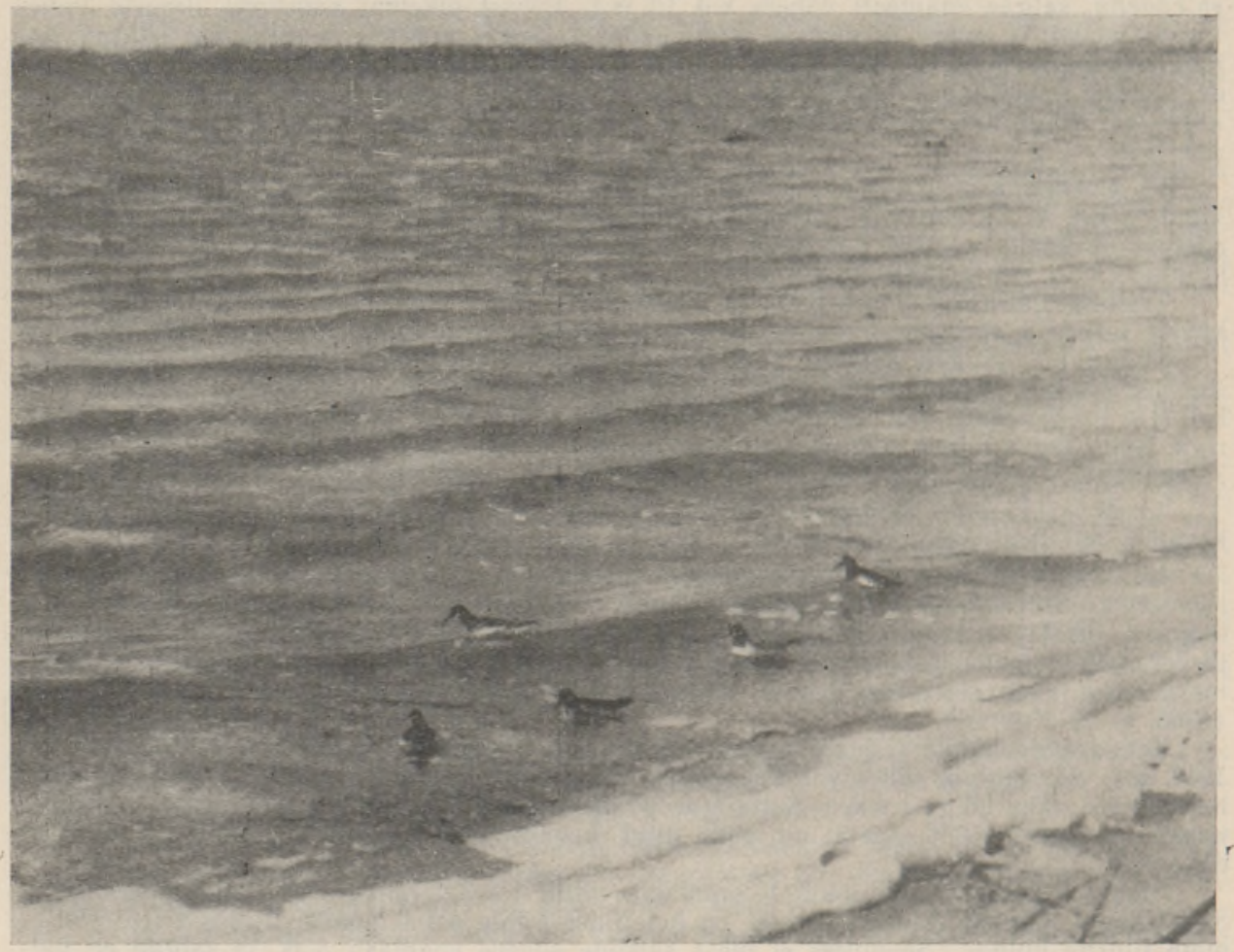

E. Kumari foto

Foto 3. Soitsjärve kirdekallas. Phalaropus lobatus*te ujusalk järvel 7. juunil 1939.

Pupastvere järvel (14. juulil kuni 30 is.) ja üksikult Soitsjärvel, Saadjärvel, Raigastvere järvel. Põhjapoolsed isendid ilmuvad juulis (1956. a. 10. juulil). Nad on küll vähearvulised, kuid kogu rändeperioodil kohatakse neid mitmetel Vooremaa järvedel. 1956. a. toimus vihitaja läbiränne Vooremaal lühikese ajal jooksul: 10. juulist 7. augustini.

20. Ve etalla ja, Phalaropus lobatus (L.). Veetallajat on autor harva kohanud (1956. a. 23. mail Soitsjärvel 17 is. ja 1. septembril Pupastvere järvel 1 is.). E. Kumari $\left[^{1}\right]$ peab teda Soitsjärvel järjekindlaks läbirändajaks. 7. juunil 1939 (foto 3) jälgis E. Kumari 21 isendit ujumas tugevasti lainetaval tormisel Soitsjärvel üsna kalda lähedal (Kursi oja piirkonnas) madalas vees. Kaks päeva hiljem oli enamik edasi rännanud, kohal viibis veel üksainus isend. E. Savi on vaadelnud Soitsjärvel seda liiki kevadel korduvalt. 1954. a. septembris vaatles üks kohalik elanik üht veetallajat, kes viibis järvel vaid pool päeva ja jätkas siis rännet.

21. Su urkoovitaja, Numenius a. arquata (L.), on kevadperioodil karakteersemaid kurvitsalisi kõigil Vooremaa järvedel. Järvede lähedastel roht- ja pōõsassoodel ning kaldaheinamaadel on ta iga-aastane pesitseja, paiguti isegi sagedasem kiivitajast.

Varaseimaks seni teadaolevaks saabumisajaks on 15. aprill (1955. aastal). Pesitsusperioodi lõppedes juuni lõpul või juuli alguses (1955) tühjenevad varsti pesitsusrajoonid. Juulikuu keskel enamasti puudub liik Vooremaa järvestikus, kuid juba pärast 20-ndat 
algab sügisrändajate saabumine. Köige intensiivsem on suurkoovitajate sügisene läbiràne juuli-augusti vahetusel ja augusti esimesel dekaadil. Rändavad $4-5$ isendilistes salkades, harva on salkade suurus ule 10 is. (näit. 12. augustil 1949 nägi E. Kumari 14 isendist koosnevat salka Saadjärve ja Soitsjärve vahelisel voorel). Enamasti toimub rànne puhassalkades. Seni on ainukeseks Vooremaal täheldatud rändekaaslaseks olnud väikekoovitaja. Augusti teisest poolest vaibub ränne, septembris lōpeb aga täiesti.

22. Vä 1 kekoovitaja, Numenius ph. phaeopus (L.). Vähearvulıse läbirändajana täheldatud ainult sügisel. Rảnne on hoos juuli lôpul: 27. juulil 1955 nägi vaatleja R. Tootsi (suul. teade) Soitsjärve idakaldal 3 isendit segasalgas 8 suurkoovitajaga, kes kỏik siin tortusid ja koos ka edasi lendasid. Augustikuus põikab see mererannikuı tavaline läbirändaja Vooremaale vaid üksıkuil juhtudel (Saadjärv, Soitsjärv).

23. Metskurvits, Scolopax rusticola L. Pupastvere järve idakalda rabamännikus kohatud haudelind. Rännet pole onnestunud vaadelda. Metskurvits oli kohal veel 21. oktoobril $1955 ; 1956$. a. puudus.

24. Tikut aja, Capella g. gallinago (L.). Oldlevinud liik kogu Vooremaa alal. Saabub mōnikord juba lumikatte ajal (nait. aastal 1955 oli juba rohkearvuliselt kohal 5. mail, kui metsas oli enam kui pōlvekôrguselt lund). Iga järve äărde jäăb mitmeid paare pesitsema. Pesi on leitud Soitsjärve aarest 6. mail 1 y37 ja 30 . juulil 1948 (A. Kumari, suuliselt), ilmset pesıtsemist on märgatud samas ka 27. mail 1949 ja teistel järvedel 1955. ja 1956. aastal. Kohe pärast pesitsusperioodi lôppu langeb tikutajate arv. Seetōttu paistab eriti silma uute tikutajate jarsk juurderänne, mis toimub juulikuu lōpust alates. Snitpeale muutub see liik, kes pesitsusajal on peidulise eluviisiga, avalikult tegutsejaks ja teda võib piki kaldaäärseid liikudes lühikeste vahemaade tagant üksikuit ja salguti üles heidutada, samuti mõnikord (harva) koos teiste kurvitsalistega (mudatilder) kalda mudapaljandeil tegutsemas näha.

Ränne on elav augustikuu läbi ja liik saavutab rände kulminatsiooni ajal mõnikord tähelepandava arvukuse (5. augustil 1956 Pupastvere järvel üldarv 90 is.), mis septembris kiiresti langeb. Hilisemaid isendeid on kohatud Saadjärvel 5 . oktoobril 1955 (2 is.) ja Soitsjärvel 24 . oktoobril 1955 (1 is.).

25. Rohukurvits, Capella media (L.). Ainult kord (19. augustil 1956) nähti Pupastvere järvest kagus üksikut isendit răndel edelasse.

26. Mudakurvits, Lymnocryptes minimus (Brünn.). 14. juulist 4. septembrini 1956. aastal viibis üks mudakurvits kogu suve Pupastvere järvel. Rändeliikumisı täheldatud ei ole, küll aga lasti 23. augustil 1955 Soitsjärvel üks mudakurvits (I. Veldre ja A. Kirsipuu, suuliselt), kes siin üksikuna peatus. 24. augustil 1955 viibis Soitsjärve loodeosa mudapaljandil üksik isend.

Seega on margitud ajavahemikus 1937-1956 Vooremaa järvestikus läbirändajatena 26 kurvitsaliste liiki, kellest iga-aastasteks läbirändajateks on 13 liiki: kiivitaja, tundratüll, väiketüll, alpi risla, tutkas, tumetilder, punajalg-tilder, heletilder, metstilder, mudatilder, vihitaja, suurkoovitaja ning tikutaja.

Rohkearvulisteks läbirandajateks k eva de 1 on 7 liiki: kiivitaja, väiketüll, tutkas, tumetilder, heletilder, suurkoovitaja, tikutaja. Rohkearvulisteks läbirändajateks s ü g i s el on 10 liiki: kiivitaja, tundratüll, alpi risla, värbrisla, tutkas, tumetilder, heletilder, mudatilder, suurkoovitaja ning tikutaja. Mōlemal rändeperi oodil esinevad rohkesti 6 liiki: kiivitaja, tutkas, tumetilder, heletilder, suurkoovitaja, tikutaja.

Vähearvulised ja juhuslikud on 9 liiki: plüü, põhjarüüt, kõvernokk-risla, suurrisla, punajalg-tilder, veetallaja, väikekoovitaja, metskurvits ja mudakurvits.

Ainult üksikuil kordadel on täheldatud Vooremaa järvedel sootildrit (Soitsjärvel), leetelindu (Pupastvere järrvel), kivirullijat (Soitsjärvel) ja rohukurvitsat (Pupastvere järvel).

\section{Kevad- ja sügisrände intensiivsuse erinevusi}

Vôrreldes kurvitsaliste kevad- ja sügisrände intensiivsust Vooremaal selgub, et kevadränne on enamikul liikidel sageli olnud nõrk. Mitmed liigid (kiivitaja, väiketüll, punajalg-tilder, suurkoovitaja, tikutaja) ilmuvad kevadel vähesel arvul siia pesitsema, kuid pōhjapoolsete populatsioonide läbiränne sellel alal on vähemärgatav. Peale pesitsejate esineb Vooremaa järvedel igal aastal väiksemal vōi suuremal arvul mittepesitsevaid hulkuvaid kurvitsalisi.

Kevadrände väiksem intensiivsus avaldub nii kurvitsaliste vaesemas liigilises koostises kui ka väiksemas isendite arvus (resp. salkade suuruses). Sama nähtust on täheldatud ka Emajōe suudme-alal ja Peipsi ranniku mitmetes osades (L. Põder, suuliselt; $\left[{ }^{4}\right]$ ). Sügisel läbirändavatest liikidest ei ole seni kevadel Vooremaa järvedel üldse kohatud tundratülli, kōvernokk-rislat, leetelindu ja väikekoovitajat. Rände intensiivsus on mōlemal rändeperioodil enam-vähem vōrdne väiketüllil, tutkal (kelle ränne juhuti on kevadel isegi elavam), heletildril, suurkoovitajal ja tikutajal. Rohkearvuliselt ilmuvad sügisrändel kiivitaja, tundratüll, alpi risla, tumetilder, heletilder, mudatilder, tikutaja ning mōnedel aastatel ka suurkoovitaja. 


\section{Erinevusi kurvitsaliste rändes paaril viimasel aastal}

Kurvitsaliste läbiränne Vooremaa järvestikust kulges 1955, aastal mõnevõrra erandlike klimaatiliste tingimuste tōttu teisiti kui 1956. aastal. 1955. aasta kevadel arenesid fenoloogilised nähtused kaua jahedana püsinud ilmastiku tôttu aeglaselt. Kaua olid järved jääkattes (jääst vabanemine toimus 4. ja 9. mai vahel). Jäälagunemisele järgnevalt ei saabunud aga kevad kiiresti ja maapind oli läbi külmunud veel kahe nädala jooksul. Varjulistes kohtades püsis lumi märgatavalt kaua (eriti kaua püsis viimane lumeviirg Saadjärve kagutipus Kukulinna voore jalamil, kust lumi kadus alles 15. ja 20. juuni vahel).

Murrang ilmastikus toimus juunikuus. 20. juunist algasid soojad ilmad. Nad vallandasid hoogsa kurvitsaliste rände, mis aga üldiselt hilines kahe ja enama nädala võrra. Kaua jahedana püsinud kevade tōttu jäi suur osa pōhjapoolsetest kurvitsalistest peatuma sobivatele, toitemaadele pesitsusalast louna pool, sealhulgas madalaveelistele toidurikastele järvedele ka meie sisemaal. Seda kinnitasid tähelepanekud eriti Pupastvere järvelt. Sellel väikesel veekogul viibis suve jooksul (kuni augusti keskpaigani) ligi pool tuhat kurvitsalist.

Seega valdav enamik siin 1955. a. juunis ja juulis tegutsenud kurvitsalisi ei teinud sel aastal läbi oma pesitsustsüklit. Juunikuus toimub kurvitsaliste pōhjapoolsetes elupaikades elav pesitsustegevus, mis ei lase tekkida arvamust, nagu oleksid nimetatud ajal Vooremaal viibinud linnud juba saabunud tagasi pōhja poolt ja nagu oleks neil pesitsemine juba lōppenud.

Alates juuli teisest poolest vōi augusti algusest toimusid Vooremaa järvedel (eeskätt Pupastvere järvel) kurvitsaliste populatsioonide segunemised siin suvekülalistena oma aega veetnud ja oma sügisrännet pōhjast alustanud isendite vahel. Selleks ajaks vähenes tunduvalt kohalolnute hulk ja augustikuus Vooremaa järvedel kohatud kurvitsalised (kuigi vähemal arvul) vōisid olla endiste asendajateks - saabunud pesitsusaladelt vōi hulgulendudelt teistest paikadest.

Kuigi 1955. a. kurvitsaliste sügisrännet Vooremaa järvede kaudu ei saa pidada massiliseks, kulges see soodsate ilmastikutingimuste juures pika perioodi kestes (juuli teine pool, august, september ja isegi oktoobri esimene pool) n. ö. venitatud rändena peaaegu kōigi liikide osas. Kogu selle aja jooksul ei olnud märgata liikide järske isenditerohkeid kogunemisi (välja arvatud kiivitaja), vaid ränne toimus ja vaibus sujuvalt.

Aastal 1956 saabus varakevad samuti hilinemisega. Järved vabanesid isegi hiljem kui 1955. aastal (Saadjärv 11. mail, teised 7.-9. maini). Ilmastik aga muutus kevadiseks varem kui eelmisel aastal. Maikuu teisel poolel algas ilmade soojenemine; maikuu lōpu ja juunikuu keskmine ōhutemperatuur ületas tunduvalt rea varasemate aastate sama aja keskmise. Kurvitsaliste saabumine ei hilinenud - kevade-esimese poole karmid ilmastikutingimused ei avaldanud rändele meie alal ebasoodsat järelmōju. Selle tōttu vōib kurvitsaliste rännet 1956. a. pidada normaalseks, s. t. sarnaseks real varasematel aastatel toimunud kevadrändega. Uhelgi Vooremaa järvel ei esinenud seesugust hulgalist kurvitsaliste varasuvist kogunemist nagu Pupastvere järvel 1955. a. Reeglipärasemalt kulges ka 1956. a. sügisränne, mille algust kōigi liikide puhul oli vōimalik täpsemalt määrata kui eelmisel aastal. Sügisränne kulges, erinevalt 1955. aastast, hoogsalt ja lühema aja jooksul. Mitmetel isendirohkelt rännanud liikidel oli ränne kõige intensiivsem juuli lôpus ja augusti alguses (tundratüllil, alpi rislal, mudatildril, tikutajal). Need ilmusid kohe rohkearvuliselt ja umbes ühe kuu jooksul (27. juulist -24 . augustini) rändasid pingsalt läbi vaatlusala. Ainult tundratüllide ja alpi rislade noored isendid saabusid märgataval arvul augusti teisel poolel ja rändasid veel septembris 12 - 30 -isendiliste salkadena. Liigid, kes ilmusid vara (kiivitaja, tumetilder), esinesid ka pika ajavahemiku jooksul. 5. juunil algas kiivitaja varasuvine ränne (s. o. mittepesitsenud vanalindude äralend). Juuli alguses ilmusid sügisrändajad, kelle arv juulikuu lōpust alates oli püsivalt kõrge (üldarv päeva jooksul $130-188$ is.), kuigi esines ka päevi, kus kiivitaja puudus. Ränne hakkas vaibuma alles septembri teisel poolel. Tumetilder (kuigi märgatavalt vähemal arvul kiivitajast) esines 15. juunist kuni 1. septembrini (augusti viimasel poolel küll ainult noored).

Kui Pupastvere järve kaudu toimus kurvitsaliste 1956, aasta sügisränne suhteliselt elavalt, siis oli see Soitsjärvel 1956. aastal tunduvalt nõrgem kui 1955. aastal. Selle üheks pôhjuseks vôib olla püsivalt kõrge veeseis suvel ja sügisel. Seda elavamat rännet tohiks seal oodata 1957. a., arvestades tugevasti muutuvaid ökoloogilisi tingimusi, mida esile kutsub 1956. a. sügisel toimunud järve allalaskmine.

Et järvede veerežiim on kurvitsaliste rändepeatustes tähtsat osa etendavaks faktoriks, seda tōendasid ilmekalt kahel viimasel (sademete suhtes tunduvalt erineval) aastal tehtud tähelepanekud Vooremaa järvedel. 1955. a. sademetevaesel suvel ja varasügisel kujunesid nii Pupastvere järvel kui ka Soitsjärvel palju soodsamad puhke- ja toitumispaigad kui ses suhtes vastupidiste tingimustega 1956. a. Nii näiteks ei olnud 1956. a. augusti lōpul ja septembri algul pärast sademeterohkeid päevi peaaegu üldse kurvitsalisi. Lakkamatult lendasid 1. septembril rislade, tundratüllide ja suured (kokku 
ca 150 is.) kiivitajate salgad Pupastvere järve kohal, kus üleujutunud mudaväljade tôttu puudusid võimalused peatumiseks. Võib arvata, et kōrgem veeseis oli pōhjuseks, miks ka Kaiavere ja Raigastvere järvel vôis kurvitsalisi (alpi risla, vihitaja, metstilder, tumetilder) 1956. a. kohata vaid harva ja väga vähesel arvul.

\title{
KIRJANDUS
}

1. K u m a ri, E., Eesti NSV linnud. Tartu, 1954.

2. Ni eth a mmer, G., Handbuch der deutschen Vogelkunde. Leipzig, 1942.

3. Ri i k o ja, H., Eesti järvede nimestik. Andmed Eesti ala järvede uurimiseks nr. 19. Tartu, 1934.

4. Р оот с я э Л. Т., О миграциях водяных и прибрежных птиц в северо-западной части Чудского озера осенью 1954 г. - Loodusuurijate Seltsi Aastaraamat, 49. köide. Tallinn, 1956.

Eesti NSV Teaduste Akadeemia

Zooloogia ja Botaanika Instituut
Saabus toimetusse

5. XI 1956

\section{О ПРОЛЕТЕ КУЛИКОВ В ВООРЕМААСКОИ ГРУППЕ ОЗЕР}

\author{
Р. Г. Линг
}

\section{Резюме}

Примерно в 20 километрах севернее Тарту, в друмлинном ландшафте, на границе Тартуского и Йыгеваского районов, находится группа эвтрофных озер, уже несколько десятков лет известная как замечательное местообитание водяных и болотных птиц. Начиная с 1936 г. в этом озерном ландшафте проводятся орнитологические наблюдения, а с 1954 г. там систематически работает автор настоящей статьи.

Два озера указанной группы - Сойтсъярв и Пупаствере, - благодаря некоторому понижению уровня воды (на озере Сойтсъярв впервые в 1929 г. и вторично осенью 1956 г., а на озере Пупаствере в 1955 г.) приобретают особое значение как места отдыха и кормежки пгролетающих через материк северных куликов. Скоплению куликов на озерах Сойтсъярв и Пупаствере благоприятствуют обширные грязевые поля, возникшие на этих озерах вследствие понижения уровня воды.

В настоящей статье сводятся воедино все сведения о пролете куликов в этом озерном ландшафте, накопленные до настоящего времени орнитологами (в частности автором статьи), работавшими в разное время на Вооремааской группе озер. На стр. 169 приведен видовой список пролетных куликов, основные времена их пролета и различные другие наблюдения над пролетными куликами.

С 1937 по 1956 гг. в Вооремааской группе озер всего зарегистрировано 26 видов пролетных куликов. Преобладающее большинство из них пролетает осенью, причем наиболее многочисленными среди них оказываются: Vanellus vanellus, Charadrius hiaticula (только осенью) Philomachus pugnax, Calidris alpina, Calidris temminckii, Tringa erythropus, Tringa glareola и Capella gallinago. Весной более или менее многочисленно пролетают представители следующих 7 видов: Vanellus vanellus, Charadrius dubius, Philomachus pugnax, Tringa erythropus, Tringa nebularia, Numenius arquata и Capella gallinago. В целом весенний пролет гораздо малочисленнее, чем осенний пролет. Вообще малочисленными являются 10 видов: Squatarola squatarola, Pluvialius apricarius, Calidris forruginea, Calidris canutus, Tringa totanus, Phalaropus lobatus, Numenius phaeopus, Scolopax rusticola, Capella media и Lymnocryptes minimus.

Изредка залетают на озера Вооремаa Tringa stagnatilis (2 находки - единственные для всей Эстонии), Crocethia alba и Arenaria interpres. 


\title{
A HALTING-PLACE FOR MIGRATORY WADERS IN THE VICINITY OF A GROUP OF LAKES AT VOOREMAA
}

\author{
R. Ling
}

\section{Summary}

About a score of kilometres north of Tartu, in a stretch of drumlin country (Est. vooremaastik) on the borders of the Tartu and Joggeva Districts, there is a group of eutrophic lakes that has long been known as a notable habitat of water and marsh birds. This region has been the scene of ornithological observations from 1936 onwards, while the author of the present article has systematically worked there since 1954 .

Two of these lakes - Soitsjärv and Pupastvere - have acquired special importance as resting and feeding places for northern wading birds in their flight across the continent, the levels of both these lakes having fallen to a certain extent (that of Soitsjärv in 1929, and for a second time in the autumn of 1956; that of Pupastvere in 1955). The extensive mud flats arising in both lakes as a result of the drop of the water level have proved a powerful source of attraction to migratory wading birds, which flock here in large numbers.

The present article summarises all available data concerning the transit of waders over this stretch of the countryside, covering all the materials gathered by various ornithologists who have visited the area of the Vooremaa lakes from time to time and correlating them with the supplementary data amassed by the author herself. On p. 169 is given a list of migratory waders according to species, showing the main times of their passage and adding various other observations of interest.

Between 1937 and 1956 no less than 26 different species of migratory waders have been identified in the region of the Vooremaa group of lakes. The overwhelming majority passes in the autumn, when the following species are represented in large numbers: Vanellus vanellus, Charadrius hiaticula (observed only in the autumn), Philomachus pugnax. Cialidris alpina, Calidris temminckii, Tringa erythropus, Tringa glareola and Capella gallinago. Seven species are more or less numerous in the spring: Vanellus vanellus, Charadrius dubius, Philomachus pugnax, Tringa erythropus, Tringa nebularia, Numenius arquata and Capella gallinago. In general the spring flight is much less numerous than the autumn flight. On the whole the following ten species are scantily represented: Squatarola squatarola, Pluvialis apricarius, Calidris ferruginea, Calidris canutus, Tringa totanus, Phalaropus lobatus, Numenius phaeopus, Scolopax rusticola, Capella media and Lymnocryptes minimus.

Of the species that occur very rarely in the region of the Vooremaa lakes the following may be mentioned: Tringa stagnatilis (observed on two occasions, the only instances recorded for the whole of Estonia), Crothetia alba and Arenaria interpres.

Academy of Sciences of the Estonian SSR, Institute of Zoology and Botany

Received

Nov. 5, 1956 